\title{
UTILIZAÇÃO DE DIFERENTES CULTURAS STARTER NO PROCESSAMENTO DE EMBUTIDO FERMENTADO DE CARNE DE CAPRINOS
}

\author{
USE OF DIFFERENT STARTER CULTURES IN PROCESSING \\ OF GOAT MEAT FERMENTED SAUSAGES
}

\section{Renata Tieko Nassu ${ }^{1}$ Lireny Aparecida Guaraldo Gonçalves ${ }^{2}$ Frederico José Beserra $^{3}$}

\section{RESUMO}

O trabalho verifica o efeito de diferentes culturas starter no processamento de embutido fermentado elaborado com carne de caprinos, avaliando $\mathrm{pH}$, atividade de água e produção de ácido lático além de determinar a aceitação sensorial e a segurança dos produtos finais obtidos. Foram testadas culturas comerciais contendo 1. Staphylococcus xylosus e Pediococcus pentosaceus; 2. mistura 50:50 de duas cepas de Pediococcus sp. e 3. Lactobacillus farciminis, Staphylococcus xylosus $e$ Staphylococcus carnosus. Os embutidos fermentados contendo as diferentes culturas, apresentaram durante o processamento comportamentos distintos $(p<0,05)$ em relação ao $\mathrm{pH}$, atividade de água e produção de ácido lático, porém a aceitação sensorial não apresentou diferença significativa $(p>0,05)$ entre os atributos estudados. A segurança do processo avaliada por cálculo de graus hora indicou que todas as culturas forneceram produtos seguros, em relação ao microrganismo Staphylococcus aureus. Concluiu-se que todas as culturas podem ser utilizadas para o processamento de embutido fermentado de carne de caprinos.

Palavras-chave: embutido fermentado, carne de caprinos, culturas starter.

\section{SUMMARY}

The effect of different starter cultures in the processing of goat meat fermented sausages was evaluated by using $\mathrm{pH}$, water activity and lactic acid production besides sensory acceptance and safety of final products were determined. Commercial starter cultures containing 1. Staphylococcus xylosus and Pediococcus pentosaceus; 2. a mixture (50:50) of two strains of Pediococcus sp 3. Lactobacillus farciminis,

\begin{abstract}
Staphylococcus xylosus and Staphylococcus carnosus were tested. During processing, fermented sausages containing the different starter cultures showed distinct behaviour in relation to $p H$, water activity and lactic acid production, although sensory acceptance did not present significative differences. The safety of products evaluated by calculation of hours-degree in obtaining the products indicated that all tested cultures resulted in safe products in relation to Staphylococcus aureus growth. Results showed that all tested cultures can be used for processing of goat meat fermented sausages.
\end{abstract}

Key words: fermented sausage, goat meat, starter culture.

\section{INTRODUÇÃO}

O processamento de carne de caprinos, com utilização de cortes não aproveitados para consumo in natura, gera maiores alternativas para sua comercialização. Vários autores relatam a utilização de carne de caprinos em produtos processados, tais como salsichas, produtos de umidade intermediária (kilishi), carne condimentada e enlatada, produtos reestruturados ("nuggets"), produtos curados e defumados, patês, embutidos cozidos, defumados e/ou fermentados, como por exemplo salames (carnes bovina, suína e ovina/caprina, contendo toucinho), "krakauer" (embutido de carne ovina/caprina e suína), "lyoner"

\footnotetext{
${ }^{1}$ Engenheiro de Alimentos, Doutor, Pesquisadora Embrapa Agroindústria Tropical. R. Doutora Sara Mesquita, 2270, Pici, 60511-110, Fortaleza, CE. E-mail: renata@cnpat.embrapa.br. Autor para correspondência.

${ }^{2}$ Química, Doutor, Laboratório de Óleos e Gorduras, Departamento de Tecnologia de Alimentos (DTA), FEA, Universidade de Campinas. CP 6091, 3081-970, Campinas, SP. E-mail: lireny@ fea.unicamp.br.

${ }^{3}$ Engenheiro Químico, Doutor, DTA, Universidade Federal do Ceará (UFC), Campus do Pici. Av. Mister Hull, 2977, Alagadiço, CP 12.168, 60356-000, Fortaleza, CE. E-mail: beserra@ufc.br.
} 
(produto de composição similar aos salames, porém sem sofrer fermentação) e salsichas tipo Viena (ZAPATA, 1994). O embutido fermentado seria uma alternativa de processamento, pois além da obtenção de um produto estável à temperatura ambiente, o sabor ácido proporcionado pela presença de bactérias lácticas auxiliaria a mascarar o sabor e aroma característicos da carne de caprinos.

As culturas starter são adicionadas a produtos cárneos para assegurar confiabilidade ao produto em termos de saúde pública, para que, em um menor tempo de fermentação, obtenha-se um produto final de qualidade e padronizado, com textura, aroma e sabor constantes, e ainda, vida de prateleira prolongada. É recomendado na fermentação obtida pela adição de cultura starter à formulação, que um $\mathrm{pH}$ de 5,3 ou menos seja alcançado dentro de um certo intervalo de tempo. Esta recomendação baseia-se no tempo em que o ambiente favorável para crescimento do microrganismo Staphylococcus aureus esteja efetivamente controlado a $\mathrm{pH}<5,3$. Durante o processamento inicial, é necessário restringir o tempo em que o produto estiver exposto a temperaturas maiores que $15,6^{\circ} \mathrm{C} \quad\left(60^{\circ} \mathrm{F}\right)$, temperatura nas quais o referido microrganismo pode se multiplicar e produzir enterotoxina (BACUS, 1986). Segundo USDA (1978), ocorrências de intoxicações alimentares nos Estados Unidos têm sido associadas à enterotoxina produzida por Staphylococcus aureus, esporadicamente presente em embutidos fermentados comerciais. Culturas starter atualmente comercializadas são geralmente compostas de mais de um microrganismo, visando somar ações características de cada uma, para se obter o efeito desejado no produto final. Os microrganismos mais utilizados na fermentação de carnes são os do gênero Lactobacillus e Pediococcus, comumente conhecidos como bactérias láticas, responsáveis pela acidificação do produto. Além das bactérias láticas, podem-se utilizar bactérias do gênero Staphylococcus não patogênicas e Micrococcus, utilizadas para a formação de coloração mais intensa e quando não for desejável a acidificação do produto. Algumas culturas comerciais utilizam a combinação de bactérias (BACUS, 1984; BACUS, 1986).

Este trabalho teve como objetivo verificar o efeito de diferentes culturas starter no processamento de embutido fermentado de carne de caprinos, acompanhando $\mathrm{pH}$, atividade de água e produção de ácido lático durante a etapa de secagem determinando a aceitação sensorial e a segurança dos produtos finais obtidos.

\section{MATERIAL E MÉTODOS}

Carne de caprinos proveniente de animais adultos, abatidos entre 16 e 18 meses, sem distinção de raça, obtida da desossa integral da carcaça inteira, foi moída em discos de $8 \mathrm{~mm}$ e congelada em freezer a $-18^{\circ} \mathrm{C}$ na forma de camadas finas de aproximadamente $2 \mathrm{~cm}$, cortada em pequenos blocos e moída conjuntamente com toucinho suíno (na proporção de $20 \%$ da massa de carne) em discos de $6 \mathrm{~mm}$. Os ingredientes de formulação utilizados foram: sal $(2,5 \%)$, mistura comercial para cura $(0,30 \%)$, isoascorbato de sódio $(0,25 \%)$, glicose $(0,50 \%)$, sacarose $(0,50 \%)$, glutamato monossódico $(0,20 \%)$, pimenta branca $(0,10 \%)$, noz moscada $(0,10 \%)$ e alho em pó $(0,10 \%)$. Foram empregadas três culturas starter comerciais (Chr. Hansen Ind. e Com. Ltda.): Floracarn SPX (Staphylococcus xylosus e Pediococcus pentosaceus); LHP (Mistura 50:50 de duas cepas de Pediococcus sp.) e Floracarn FF-2 (Lactobacillus farciminis, Staphylococcus xylosus e Staphylococcus carnosus), cada uma correspondendo a um tratamento, todos adicionados na proporção $0,02 \%$. A carne, gordura e ingredientes foram colocados em misturadeira e embutidos em tripas de colágeno reconstituído (calibre de $45 \mathrm{~mm}$ ) e mantidas em uma câmara de umidade relativa e temperatura controladas durante 14 dias. A programação de temperatura e umidade relativa (UR) foram as seguintes: primeiro dia, temperatura $22-23^{\circ} \mathrm{C} /$ U.R. $85-95 \%$; segundo dia, $18-20^{\circ} \mathrm{C} / 80-$ $90 \%$ e terceiro dia em diante, $12-15^{\circ} \mathrm{C} / 70-80 \%$. Foram processadas duas bateladas de $3 \mathrm{~kg}$ de produto por tratamento. Durante o processamento, foram coletados aleatoriamente três gomos de amostra de cada tratamento, sendo as análises realizadas no mínimo em triplicata, determinando-se $\mathrm{pH}$, segundo técnica descrita por TERRA \& BRUM (1985); atividade de água (Aw), utilizando aparelho medidor de atividade de água, marca Decagon Devices Inc., modelo Aqualab CX-2 e teor de ácido lático segundo ACTON et al. (1972) nos dias 0, 1, 2, 5, 7 e 14. A 48 horas, foram coletadas amostras para análise de Staphylococcus aureus segundo ICMSF (1988).

O cálculo para verificar a segurança do processo foi realizado de acordo com o AMERICAN MEAT INSTITUTE (1982), ou seja, avaliando o número de graus Fahrenheit $\left({ }^{\circ} \mathrm{F}\right)$ que a superfície do produto ou a câmara de fermentação pode atingir acima de $15,6^{\circ} \mathrm{C}$ até que o produto atinja o $\mathrm{pH} 5,3$, multiplicado pelo tempo em horas.

O teste de análise sensorial foi realizado após o tempo de maturação na câmara. Foram coletadas aleatoriamente aproximadamente $30 \mathrm{~g}$ de 
amostra, correspondentes a duas fatias finas, por tratamento/cultura, sendo realizada uma única sessão onde foram apresentadas as três amostras separadamente (apresentação monádica). Foi aplicado o teste sensorial de aceitação, utilizando-se escala hedônica estruturada de 9 pontos, variando de desgostei muitíssimo (nota 1) a gostei muitíssimo (nota 9). Os testes foram realizados em cabines individuais no Laboratório de Análise Sensorial de Alimentos da Embrapa Agroindústria Tropical. Utilizaram-se 30 provadores não treinados para avaliação das amostras. Foram avaliados aceitação global e os atributos aparência, aroma, sabor e textura (MEILGAARD et al., 1987)

Os resultados obtidos nas análises físicoquímicas e nos testes de aceitação sensorial foram avaliados através de análise de variância univariada (ANOVA) e teste de Tukey entre as médias obtidas para cada tratamento, através do programa estatístico SAS for Windows, versão 6.12 (SAS, 1996)

\section{RESULTADOS E DISCUSSÃO}

A evolução do $\mathrm{pH}$ (Figura 1) indicou um decréscimo de $\mathrm{pH}$ para todos os produtos, porém em caráter menos acentuado para o tratamento com cultura SPX. A velocidade de queda do $\mathrm{pH}$ influencia diretamente a perda de água do produto, consequentemente a Aw; quando o $\mathrm{pH}$ se aproxima do ponto isoelétrico das proteínas, há maior perda de água. Portanto, quanto mais rápida a queda de $\mathrm{pH}$, maior a velocidade de perda de água, levando a menores valores de Aw (BACUS, 1984). Este fenômeno pode ser observado na figura 2 , onde está apresentada a evolução da Aw dos produtos. O tratamento contendo a cultura SPX, que apresentou menor queda de $\mathrm{pH}$, também apresentou maior Aw, pois perdeu menos água durante o processamento. As outras amostras, por apresentarem maior queda

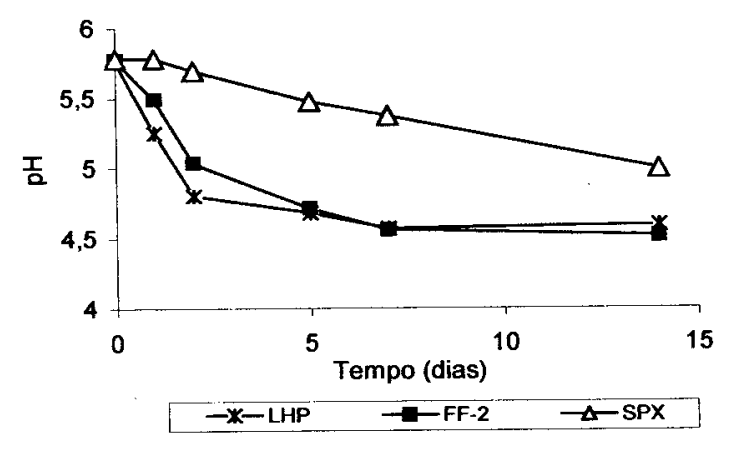

Figura 1 - Evolução do pH dos embutidos fermentados de carne de caprinos formulados com diferentes culturas starter de $\mathrm{pH}$, perderam mais água, apresentando consequentemente menores valores de Aw. Os tratamentos com as culturas LHP e FF-2 atingiram o pH de 5,3 ou menor recomendado pelo AMERICAN MEAT INSTITUTE (1982) em 48 horas, com valores de 4,8 e 5,0, respectivamente, porém o tratamento com cultura SPX não atendeu esta recomendação, atingindo $\mathrm{pH}$ de 5,7. Os graus-hora utilizados para que as amostras atingissem o pH ideal, foram calculados considerando o tempo de 24 horas a $25^{\circ} \mathrm{C}\left(77^{\circ} \mathrm{F}\right)$ e 24 horas a $21,3^{\circ} \mathrm{C}\left(70,3^{\circ} \mathrm{F}\right)$ para os tratamentos com culturas LHP e FF-2 e para SPX, mais 120 horas a $16,2^{\circ} \mathrm{C}\left(61,2^{\circ} \mathrm{F}\right)$. Os resultados dos cálculos para os três tratamentos foram: 655 graus-hora para LHP; 655 graus-hora para FF-2, e 799 graus-hora para SPX. Apesar do tratamento com a cultura SPX não ter atingido o $\mathrm{pH}$ recomendado em 48 horas, calculando-se os graushora do processo, observa-se que os valores estão compatíveis com a condição estabelecida pelo AMERICAN MEAT INSTITUTE (1982), que exige que o número de graus hora seja menor que 1200 . Os outros tratamentos também estão dentro dos padrões. Amostras coletadas após o período de 48 horas, durante $\mathrm{o}$ qual foram submetidas a temperaturas mais altas, apresentaram contagens de S. aureus $<10 \mathrm{UFC} / \mathrm{g}$ para todos os tratamentos, indicando que não houve crescimento deste microrganismo durante este período.

$\mathrm{Na}$ figura 3, verifica-se que o tratamento com a cultura FF-2 apresentou maior produção de ácido lático, o que era esperado por se tratar de uma cultura de fermentação extra-rápida devido à presença do microrganismo Lactobacillus farcimini em sua composição. Sabe-se que os microrganismos do gênero Lactobacillus são mais acidificantes que os Pediococci (BACUS, 1984), presentes nas outras duas culturas utilizadas neste experimento. Os valores finais de $\mathrm{pH}$, Aw e porcentagem de ácido

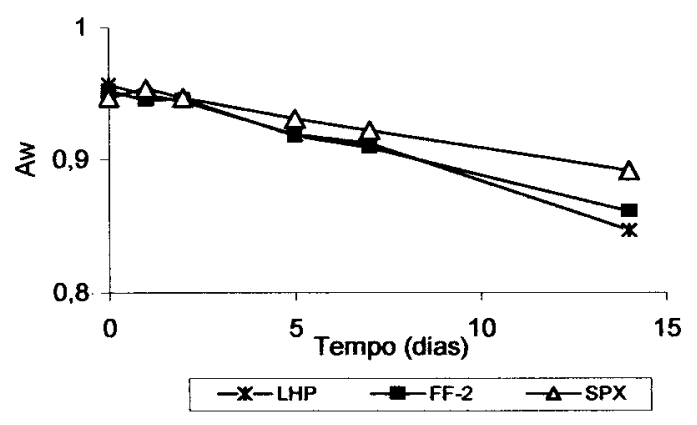

Figura 2 - Evolução da Aw dos embutidos fermentados de carne de caprinos formulados com diferentes culturas starter

Ciência Rural, v. 32, n. 6, 2002. 


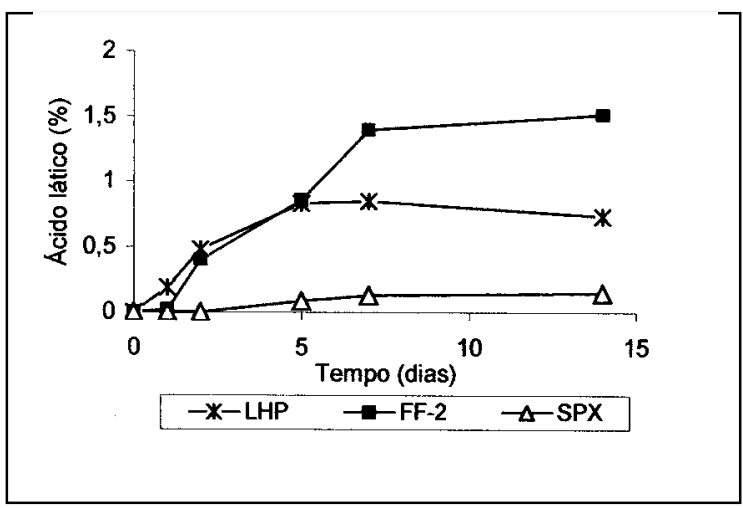

Figura 3 - Evolução da produção de ácido lático para embutidos fermentados de carne de caprinos formulados com diferentes culturas starter

lático finais dos produtos obtidos são apresentados na tabela 1. O tratamento com cultura SPX apresentou maior $\mathrm{pH}$ e menor porcentagem de ácido lático, enquanto o tratamento com FF-2 apresentou o menor valor de $\mathrm{pH}$ e maior porcentagem de ácido lático. Os valores de $\mathrm{pH}$ e ácido lático apresentaramse diferentes entre os tratamentos $(p<0,05)$. Já os valores de Aw não apresentaram diferença significativa $(p>0,05)$ para os tratamentos com culturas LHP e FF-2, que foram significativamente menores $(\mathrm{p}<0,05)$ do que o valor apresentado pelo tratamento com cultura SPX. O tratamento com cultura SPX, que é menos acidificante que as demais, apresentou maior Aw, devido à maior retenção de água pelas proteínas, que demoraram a atingir seu ponto isoelétrico, dificultando a saída da água, levando a uma maior Aw no produto. Quanto ao tratamento com cultura LHP, uma mistura de duas cepas de Pediococcus sp., parece ter aumentado seu potencial de produção de ácido, pois alcançou valores de $\mathrm{pH}$ baixos logo no início do processo, tal como o tratamento contendo Lactobacillus, porém com menor intensidade que esta cultura, apresentando valores intermediários.

Os valores de $\mathrm{pH}$ e porcentagem de ácido lático encontrados neste experimento para o tratamento com cultura LHP, uma mistura de duas cepas do microrganismo Pediococcus sp., são similares aos relatados em estudo conduzido por ACTON et al. (1972), no qual foram encontrados valores de $\mathrm{pH}$ finais variando de 4,5 a 4,7 e de ácido lático, de 0,5 a $1,5 \%$, ao se utilizar culturas de Pediococcus cerevisae em embutidos fermentados. DELLAGLIO et al. (1996) relatam valores de 0,246 a 1,544\% de ácido lático em embutido seco italiano, similares aos encontrados no presente experimento. ZALACAIN et al. (1995) em um estudo comparativo entre salames com formulação
Tabela 1 - Valores finais de $\mathrm{pH}$, Aw e porcentagem de ácido lático para embutidos fermentados de carne de caprinos formulados com diferentes culturas starter.

\begin{tabular}{lccc}
\cline { 2 - 4 } & \multicolumn{3}{c}{ TRATAMENTO } \\
\cline { 2 - 4 } & SPX & LHP & FF-2 \\
\hline $\mathrm{pH}$ & $4,99 \mathrm{a}$ & $4,59 \mathrm{~b}$ & $4,51 \mathrm{c}$ \\
Aw & $0,89 \mathrm{a}$ & $0,85 \mathrm{~b}$ & $0,86 \mathrm{~b}$ \\
Ácido lático (\%) & $0,15 \mathrm{c}$ & $0,73 \mathrm{~b}$ & $1,51 \mathrm{a}$ \\
\hline
\end{tabular}

Amostras seguidas das mesmas letras na mesma linha não diferem $(\mathrm{p}>0,05)$ pelo teste de Tukey.

tradicional com cultura starter contendo os microrganismos Lactobacillus plantarum e Staphylococcus carnosus e outro tendo adicionado lipase, relatam valores de $\mathrm{pH}$ de 4,71 para a formulação elaborada com cultura starter. Este valor está bem próximo ao obtido neste experimento para a amostra com cultura que contém os microrganismos Lactobacillus e $\boldsymbol{S}$. carnosus/S. xylosus, cujo valor de $\mathrm{pH}$ final obtido foi de 4,51. STAHNKE ( 1995a, 1995b, 1995c) em uma série de estudos, relata dados químicos, microbiológicos e sensoriais em embutidos secos fermentados com Staphylococcus xylosus a diferentes temperaturas e níveis de ingredientes, entre eles a combinação com a cultura de Pediococcus pentosaceus. Amostras que continham a combinação das duas culturas apresentaram menor $\mathrm{pH}$ devido à adição da cultura acidificante. Amostras submetidas à temperatura de fermentação de $25^{\circ} \mathrm{C}$ durante 48 horas e submetidas à secagem a $15^{\circ} \mathrm{C}$ por 26 dias, com a combinação das duas culturas, similares à cultura SPX deste experimento, também apresentaram queda semelhante a este experimento, isto é, o pH de 5,3 não foi atingido em 48 horas, variando de 5,4 a 5,9. O tratamento que utilizava a combinação das duas culturas e glicose na formulação atingiu valores de pH de 5,1 em 7 dias e 4,9 em 14 dias, similares aos dados obtidos nos experimentos deste trabalho.

A análise sensorial indicou valores médios que variaram de 5,5 a 5,9 para aceitação global. Os valores médios para aceitação global, aroma, sabor e textura não apresentaram diferença significativa $(p>0,05)$ para todos os tratamentos (Tabela 2). Houve diferença significativa apenas para o atributo aparência, no qual o tratamento com cultura SPX apresentou menor valor, em comparação com os outros tratamentos. Os comentários espontâneos feitos pelos provadores nas fichas de análise sensorial, tanto na sessão para aceitação global quanto para os atributos, não indicaram nenhuma tendência marcante entre os 
Tabela 2 - Valores médios de notas de aceitação global, aparência, aroma, sabor e textura para embutidos fermentados de carne de caprinos formulados com diferentes culturas starter.

\begin{tabular}{lccc}
\cline { 2 - 4 } & \multicolumn{3}{c}{ TRATAMENTO } \\
\hline Avaliação sensorial & SPX & LHP & FF-2 \\
\hline Aceitação global & $5,9 \mathrm{a}$ & $5,5 \mathrm{a}$ & $5,6 \mathrm{a}$ \\
Aparência & $4,7 \mathrm{~b}$ & $5,7 \mathrm{a}$ & $6,1 \mathrm{a}$ \\
Aroma & $4,7 \mathrm{a}$ & $5,0 \mathrm{a}$ & $4,4 \mathrm{a}$ \\
Sabor & $5,7 \mathrm{a}$ & $5,3 \mathrm{a}$ & $5,3 \mathrm{a}$ \\
Textura & $5,9 \mathrm{a}$ & $6,0 \mathrm{a}$ & $5,9 \mathrm{a}$ \\
\hline
\end{tabular}

Amostras seguidas mesmas letras na mesma linha, não diferem ( $\mathrm{p}>0,05)$ pelo teste de Tukey.

tratamentos. Dentre os comentários, destacaram-se observações isoladas sobre a acidez do produto, para a amostra FF-2 e outras sobre sabor "rançoso", "sabão", que poderiam ser atribuídas à oxidação da gordura dos produtos ou mesmo devido à ação lipolítica dos microrganismos presentes nas culturas utilizadas.

\section{CONCLUSÃO}

Os resultados deste experimento demonstraram que todas as culturas podem ser utilizadas, pois pode-se obter através delas produtos seguros em relação ao crescimento de $S$. aureus.

\section{AGRADECIMENTOS}

À Chr. Hansen Ind. e Com. Ltda., que gentilmente forneceu as culturas starter para este experimento.

\section{REFERÊNCIAS BIBLIOGRÁFICAS}

ACTON, J.C.; WILLIANS, JG.; JOHNSON, M.G. Effects of fermentation temperature on changes in meat properties and flavor of summer sausage. Journal of Milk Food Technology, Shelbyville, v. 35, n.5, p.264-268, May, 1972.

AMERICAN MEAT INSTITUTE (AMI). Good manufacturing practices, fermented dry and semi-dry sausage. Washington DC : American Meat Institute, 1982.
BACUS, J. Update: meat fermentation 1984. Food Technology, Chicago, v.38, n.6, p.59-69, June, 1984.

BACUS, J. Utilization of microrganisms in meat processing. Letchworth : Research Studies, John Wiley \& Sons, 1986. $170 \mathrm{p}$.

DEllaGliO, S.; CASIRAGHI, E.; POMPEI, C. Chemical, physical and sensory attributes for the characterization of an Italian dry-cured sausage. Meat Science, Essex, v.42, n.1, p.25-35, 1996.

ICMSF (International Commission on Microbiological Specifications for Foods). Micro-organisms in foods 1Their significance and methods of enumeration 2.ed. Toronto: University of Toronto, 1988. 436p.

MEILGAARD, M.; CIVILlE, G.V.; CARR, B.T. Sensory evaluation techniques. Boca Raton : CRC, 1987. V.2. 159 p.

SAS. Sas Institute Inc. Cary, NC, 1996.

STAHNKE, L.H. Dried sausages fermented with Staphylococcus xylosus at different temperatures and with different ingredients levels - Part I. Chemical and bacteriological data. Meat Science, Essex, v. 41, n.2, p. 179-191, 1995a.

STAHNKE, L.H. Dried sausages fermented with Staphylococcus xylosus at different temperatures and with different ingredients levels - Part II. Volatile components. Meat Science, Essex, v. 41, n.2, p. 193-209, 1995b.

STAHNKE, L.H. Dried sausages fermented with Staphylococcus xylosus at different temperatures and with different ingredients levels - Part III. Sensory evaluation. Meat Science, Essex, v.41, n.2, p. 211-223, 1995c.

TERRA, N.N., BRUM, M.A.R. Carne e seus derivados - Técnicas de controle de qualidade. São Paulo : Nobel, 1985. 121p.

USDA. Is there poison in your pepperoni? Meat Processing, Hinsdale, v.17, n.2, p.22-26, 98-103, Feb. 1978.

ZALACAIN, I.; ZAPELENA, M.J.; ASTISARÁN, I.; et al.. Dry fermented sausages elaborated with lipase from Candida cylindracea. Comparison with traditional formulations. Meat Science, Essex, v. 40, n.1, p. 55-61, 1995.

ZAPATA, J.F.F. Tecnologia e comercialização da carne ovina. In: SEMANA DA CAPRINOCULTURA E DA OVINOCULTURA TROPICAL BRASILEIRA, 1994, Sobral. Anais... Brasília : EMBRAPA-SPI, 1994. p. 115-128. 